Abstract CPC-034 Table 1

\begin{tabular}{|c|c|c|c|c|c|c|c|c|c|}
\hline & N (R-CHOP) & $\%$ Pt_PP & $\%$ Pt_FN & $\%$ Cycles_FN & Incidence FN_1 ${ }^{\text {st }} C y$ & Incidence FN_other Cy & $2^{\text {nd }}{ }_{\text {Prophylaxis }}$ & $\begin{array}{l}\text { AvrDays } \\
\text { Hosp/FN episode }\end{array}$ & $\begin{array}{l}\text { AvrDays to } \\
\text { ANC recovery }\end{array}$ \\
\hline RMP & 75 & $37.3(28 / 75)$ & $28.6(8 / 28)$ & $7.7(14 / 181)$ & 0.18 & 0.06 & $30(40)$ & 8.4 & 12.6 \\
\hline B & 104 & $27.9(29 / 104)$ & $24.1(7 / 29)$ & $5.9(10 / 168)$ & 0.10 & 0.05 & $34(32.7)$ & 9.2 & 8.6 \\
\hline
\end{tabular}

Mean age $=72$ y (both); Gender $=46.4 \% \mathrm{~m}, 53.6 \% \mathrm{f}(\mathrm{RMP}) ; 31 \% \mathrm{~m}, 69 \% \mathrm{f}(\mathrm{B}) ; \mathrm{NHLB}=75 \%(\mathrm{RMP}), 72 \%$ (B)

\section{CPC-035 COMPASSIONATE USE: PHARMACOVIGILANCE}

\section{doi:10.1136/ejhpharm-2013-000276.492}

G Saibene, E Togliardi, F Brera, F Festinese, M Mazzer, G Antonacci, V Di Mauro. Fondazione IRCCS Istituto Nazionale Dei Tumori, Farmacia, Milano, Italy

Background The compassionate use of drugs in Italy is a way of using drugs available in foreign countries but not in Italy. They have the authorization for the same therapeutic purpose but are not available on the market, however they are in clinical trials (CTs) or have been tested in phase III or - if the patient is in a critical condition - have been successful in phase II CTs.

As regards evaluating the efficacy of the treatment, a basic aspect of the CT is to evaluate the safety of the drugs used. Great attention is focused on this theme with sponsored CTs; in fact by law (decree 211/2003) the subjects liable for pharmacovigilance are expressly listed and stress is put on reporting adverse drug reactions (ADRs). Regarding the use of compassionate drugs, there are no laws regulating the reporting of ADRs.

Purpose To find out how any reports of possible ADRs emerging from compassionate studies are managed in ordinary clinical practise.

Materials and Methods For this purpose the database used in our organisation was essential: all of our centre's CTs are listed there. The number of CTs classified by type (for profit, not-for-profit, compassionate) was extracted, focusing on the compassionate use CTs in particular. Then the number of patients treated was drawn from it as well as the pathologies and the ADRs pointed out during meetings with the physicians.

Results From this analysis it appeared that in our centre 197 studies (st) are active: 147 are for profit, 27 not-for-profit and 23 compassionate. Among these last ones, 8 are active in the sarcoma department, 5 in haematology, 3 in paediatrics, 6 in medical oncology and 1 in urology. The pathologies being examined are: GIST 4 active sts, 6 patients (pts), Hodgkin's lymphoma 1 st (2 pts), T-cell lymphoma 1 st (1 pt), myeloma 2 sts ( 1 and 15 pts), thyroid carcinoma 1 st (1pt), bone metastases 1 st (4 pts), melanoma 2 sts (1 and $30 \mathrm{pts}$ ), villonodular tenosynovitis 1 st (4 pts), prostatic adenocarcinoma 1 st (4 pts), breast cancer 2 sts ( 3 and 2 pts), leiomyosarcoma 1 st (2 pts), myxoid liposarcoma 1 st (6 pts), brain stem glioma 1 st (8 pts), NET 1 st (17 pts), acoustic neuroma 1 st (1 pt), idiopathic myelofibrosis 1 st (1 pt), LLC 1 st (1 pt). Although the CTs for compassionate use are fewer than other kinds of trials and require a very low number of treated pts - also because it is a matter of a named patient use and in particular conditions - this does not justify not reporting ADRs. As such drugs are used for critical pts and often for non-approved uses, it seems useful to focus on this aspect, as it allows to more and better investigations on the side of the safety of the drugs.

Conclusions The results obtained underline the necessity of better awareness of the problem. As far as our centre is concerned, the results led us to hold meetings with the physicians and to plan interventions in order to make them aware of the problem and in order to start a process of pharmacovigilance with compassionateuse drugs.

No conflict of interest.

\section{CPC-036 CONNECTION BETWEEN BONE FRACTURES, VITAMIN D LEVEL AND LOW-ENERGY FALLS IN HOSPITALISED ELDERLY PATIENTS}

doi:10.1136/ejhpharm-2013-000276.493

A Bor, P Doró, M Matuz, Z Biczók, R Viola, G Soós. Univeristy of Szeged, Department of Clinical Pharmacy, Szeged, Hungary

Background The ageing of the population in developed countries is a growing problem today. Prevalence of chronic diseases, such as osteoporosis, increases with age. It is estimated that 900,000 people ( $9 \%$ of the population) above the age of fifty suffer from osteoporosis in Hungary. This condition greatly increases the risk of fractures of vertebra and the hip bone, which often lead to fatal consequences. Many studies have proven that a low vitamin $\mathrm{D}$ level increases the risk of bone fractures. Adequate vitamin $\mathrm{D}$ level is essential to prevent bone loss and structural damage of the bone matrix, which also prevents fractures.

Purpose To compare vitamin D levels of hospitalised hip fracture patients with hospitalised non-fractured patients, as well as to detect the prevalence of low-energy falls, and to analyse the differences between the groups.

Materials and Methods The fractured group was recruited from the Traumatology Department and the control group was recruited from the Internal Medicine Department. The control group was matched according to age and gender. Vitamin D levels were measured with an ELISA kit and were expressed in $\mathrm{ng} / \mathrm{ml}$. Subjects were asked about previous falls during a personal interview.

Results Twenty-two patients were in the fractured group (mean age 84.09 years, $\mathrm{SD} \pm 6.78)$ and 33 patients were in the control group (mean age 80.52 years, $\mathrm{SD} \pm 6.56$ ). The mean vitamin $\mathrm{D}$ level was $33.13 \mathrm{ng} / \mathrm{ml}$ in the fractured group and $39.7 \mathrm{ng} / \mathrm{ml}$ in the control group $(\mathrm{P}=0.230)$. However, the vitamin $\mathrm{D}$ level was under the normal range $(30-60 \mathrm{ng} / \mathrm{ml})$ in the majority of patients in both groups. Patients of the fractured group reported considerably more falls within one year than the control group.

Conclusions Since the difference in vitamin D levels was not significant between the investigated groups, other risk factors could be responsible for fractures besides the low vitamin $\mathrm{D}$ level. A noteworthy factor may be falls, because more than half of the fractured patients reported multiple falls in the previous year.

No conflict of interest.

\section{CPC-037 CONTINUITY OF CARE IN PAEDIATRIC PATIENTS: PROSPECTIVE STUDY AT HOSPITAL DISCHARGE}

doi:10.1136/ejhpharm-2013-000276.494

'LZ Kaestli, 'C Fonzo-Christe, ${ }^{2} \mathrm{~S}$ Chalier, ${ }^{1 P}$ Bonnabry. ${ }^{1}$ Geneva University Hospitals (HUG), Pharmacy, Geneva, Switzerland; ' ${ }^{2}$ Geneva University Hospitals (HUG), Pediatric Service, Geneva, Switzerland

Background A variety of problems can occur at hospital discharge. Optimization of this multidisciplinary process is essential to ensure a high quality of care.

Purpose To assess drug problems encountered by paediatric patients at hospital discharge; prospective clinical study. 